Primljen / Received: 14.10.2011.

Ispravljen / Corrected: 21.2.2012.

Prihvaćen / Accepted: 12.3.2012.

Dostupno online / Available online: 25.4.2012.

\section{Probabilistic analysis of seismic performance of reinforced concrete frame structures}

\section{Authors:}

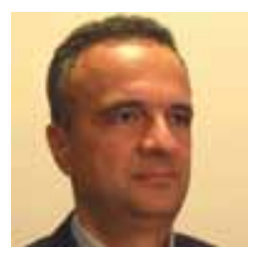

Asst. Prof. Srdan Janković, PhD. CE

University of Monte Negro

Faculty of Civil Engineering

srdjan@t-com.me

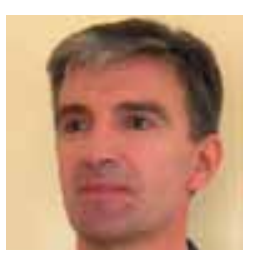

Prof. Mladen Ulićević, PhD. CE

University of Monte Negro

Faculty of Civil Engineering

mladen@t-com.me

\section{Srdan Janković, Mladen Ulićević}

\section{Probabilistic analysis of seismic performance of reinforced concrete frame structures}

The seismic performance of reinforced concrete frame structures of varying numbers of storeys, designed according to EC 8 and EC 2, is analyzed in the paper. The analysis is based on the probabilistic approach in which all identified incidental and indeterminate occurrences are taken into account. Performance of reinforced concrete frame structures is presented through maximum inter-storey drift values, while intensity is defined through spectral response of acceleration. The analysis results show that seismic response values increase by 31 to 54 percent if incidental and indeterminate occurrences are taken into account.

Key words:

maximum relative inter-storey drift, response spectrum, RC frame structure, EC 8, seismic hazard curve

Pregledni rad

Srdan Janković, Mladen Ulićević

\section{Probabilistička analiza seizmičkog ponašanja $A B$ okvirnih konstrukcija}

$U$ radu je analizirano seizmičko ponašanje armiranobetonskih okvirnih konstrukcija različitih katnosti, projektiranih prema EC 8 i EC 2. Pri ovoj analizi primijenjen je probabilistički pristup gdje su u proračun uzete sve identificirane slučajnosti i neodređenosti. Ponašanje AB okvirnih konstrukcija prikazano je pomoću maksimalnog pomaka katova (engl. drift), dok je kao mjera intenziteta uzet spektralni odgovor ubrzanja. Rezultati provedenih analiza pokazali su da se seizmički odgovori uvećavaju za $31 \%$ do $54 \%$ ako se proračunom obuhvate slučajnosti i neodređenosti.

Ključne riječi:

max. relativno pomicanje katova, spektar odgovora, AB okvirna konstrukcija, EC 8, seizmička hazardna krivulja

Übersichtsarbeit

Srdan Janković, Mladen Ulićević

\section{Probabilistische Analyse des seismischen Verhaltens von Stahlbeton Rahmenkonstruktionen}

In der Arbeit wurde das seismische Verhalten von Stahlbeton-Rahmenkonstruktionen verschiedener Stockwerkhöhen, die gemäß EC 8 und EC 2 projektiert wurden gemessen. Bei dieser Analyse wurde die probalistische Vorgehensweise angewandt, wo alle identifizierten Zufälle und Unbestimmtheiten miteinberechnet wurden. Das Verhalten von AB-Rahmenkonstruktionen wurde mithilfe von maximalen Stockwerkverschiebungen (engl. Drift) gemessen, während als Intensitätsmaß die spektrale Beschleunigungsantwort genommen wurde. Die Resultate der durchgeführten Analysen haben gezeigt, dass die seismischen Antworten um 31 \% bis 54 \% steigen, wenn in die Berechnung Zufälle und Unbestimmtheiten miteinkalkuliert werden.

\section{Schlüsselwörter:}

maximale relative Stockwerkverschiebung, Antwortspektrum, AB-Rahmenkonstruktion, EC 8, seismische Gefährdungskurve 


\section{Introduction}

In almost all seismic codes that are currently in use, the collapse prevention is set out as the basic design requirement (also called the performance objective) which implies, according to EC8, [1], that the structure designed in line with this code should withstand, with an adequate degree of reliability, the design earthquake level without local or global collapse, and retain its structural integrity and load bearing capacity after the earthquake. The design earthquake level is based on the $10 \%$ probability of exceedance in 50 years or, equivalently, on the return period of 475 years (in the following text, this seismic hazard is marked with $10 \% / 50$ ). By prescribing adequate provisions referring to dimensioning and detailing, the EC8 implicitly states that the combination of load bearing capacity and ductility obtained in this way provides the safety factor against the local and global failure between 1.5 and 2 , [2]. In order to control this performance level, the performance of structures under the impact of the design earthquake must realistically be predicted.

However, a considerable level of uncertainty (epistemic uncertainty) and randomness (aleatory uncertainty) can not be avoided in the analysis of structures subjected to seismic action. They are the result of our inability to precisely describe and characterize real-life phenomena. The term uncertainty is often used to describe an error resulting from to our insufficient knowledge about a physical system/phenomenon, while the term randomness is related to our inability to account for natural variance, i.e. to understand factors that influence the phenomenon under study. In literature, the term uncertainty is quite frequently used to denote both the uncertainty, as defined above, and the randomness. A large number of uncertainties existing in earthquake engineering can be divided into three categories: uncertainty in defining the earthquake intensity, uncertainty in determining the seismic behaviour, and uncertainty in the prediction of capacities. The first two uncertainties will be further elaborated in this paper. Due to uncertainty and randomness, the seismic performance of structures can not be predicted with a hundred percent reliability during analysis of seismic response, i.e. the final decision about whether the facility is seismically safe or not can not be made, in an absolute sense, upon completion of the analysis. Although uncertainties and randomness, present in the prediction of future load and behaviour of structures, actually exist in all types of structures and loads, and despite the fact that they have been included in technical regulations through safety coefficients, these occurrences have not, until recently, been systematically evaluated and included in the analysis of seismic behaviour. Aware of this fact, the authors of the document [3] propose a probabilistic approach for steel frame structures, according to which an acceptable behaviour of structures is quantified in such a way that the probability of exceedance of a predefined behaviour in a defined time span will be lower than the prescribed probability. Thus, the confidence level is measured for the Collapse Prevention objective, and this in such a way that the probability of the local or global collapse is less than $10 \%$ in 50 years.

Such definition of the design objective for collapse prevention is similar to, but also somewhat different from, most of the applicable seismic codes (including EC8). In these codes, earthquake intensities are defined probabilistically, whereas verification of structural behaviour is conducted deterministically, i.e. the response obtained (maximum value in case of three earthquakes, and average value in case of seven or more earthquakes) for the given earthquakes is compared with an acceptable predefined response. The principal difference in these approaches is that the document [3] recognizes possibility that the earthquake with high probability of occurrence can cause damage that exceeds the level of Collapse Prevention and, similarly, that the earthquake with lower probability of occurrence can cause damage that is lower than the damage corresponding to the Collapse Prevention performance level. In other words, the probability of $10 \%$ in 50 years is required so as to ensure that the damage does not exceed the collapse prevention level for all earthquake intensities that can occur at a given location. The main performance objective, aimed at ensuring that the structure will have the probability of less than $10 \%$ in 50 years for Collapse Prevention, can be defined with the following expression, [4]:

$\phi \hat{C} \geq \gamma \gamma_{a} \hat{D}^{P_{0}}$

Where:

$\hat{C} \quad$ - median of the structure capacity

$\hat{D}^{P_{0}}$ - median of the seismic response obtained by structural analysis for seismic hazard of $10 \%$ in 50 years

$\gamma \quad$ - factor of variability of the seismic response

$\gamma_{a}$ - factor of uncertainty of seismic analysis which accounts for errors due to use of simpler methods of seismic analysis

$\phi \quad$ - resistance factor that accounts for uncertainty and randomness inherent in the prediction of structural capacity..

The terms $\hat{C}$ and $\hat{D}^{P_{0}}$ could be named as evaluations 'of the first order". If there are no uncertainty and randomness, i.e. no dispersion of results, during definition of the seismic response and capacity, it would be sufficient to meet the condition in which $\hat{C} \geq \hat{D}^{P_{0}}$. Correction factors $\gamma$ i $\gamma_{\text {a }}$ take into account the probability that the seismic response is greater than $\hat{D}^{P_{0}}$ while factor $\phi$ accounts for the possibility of capacity being less than $\hat{C}$.

This paper analyses seismic behaviour of R/C frames with different number of storeys $(4,6,8$, and 12 storeys) designed in line with $E C 8$, taking into account uncertainties and randomness. At that, the probabilistic approach is applied, which is, although initially explained on an example of seismic behaviour of steel frame structures presented in literature [3, 4], generally independent from the structural material used. In other words, 
the way in which all members on the right side of the expression (1) are defined will be described, and their values for $R / C$ frames under study, will be calculated in the following sections.

\section{Basic information about $\mathrm{R} / \mathrm{C}$ frames and their modelling}

Two-dimensional nonlinear dynamic analyses were conducted for four prototypes of R/C frames with different number of storeys (4, 6, 8 and 12), which had been previously designed and dimensioned in accordance with European codes [1] and [5]. The frames are located on the site with the peak ground acceleration $\alpha_{g}=0.36 \mathrm{~g}$ for the return period of 475 years. Frames are founded on a stable and firm soil. Each frame has a R/C floor slab $5.4 \mathrm{~m}$ in width and $15 \mathrm{~cm}$ in thickness. All storeys are of equal height (3.2 m). High class of ductility DCH, [1] has been adopted for all frames.

The following beam and column dimensions have been adopted:

\begin{tabular}{|c|c|}
\hline Number of storey frame & $\begin{array}{l}\text { Adopted beam } \\
\text { and column dimensions }\end{array}$ \\
\hline 4 & $\begin{array}{l}\text { The dimensions of the all beams } \\
\text { and columns are } 25 / 50 \mathrm{~cm} \text { and } \\
40 / 40 \mathrm{~cm} \text {, respectively }\end{array}$ \\
\hline 6 & $\begin{array}{l}\text { The dimensions are: all beams } \\
30 / 55 \mathrm{~cm} \text {, exterior columns: } \\
\text { 45/45 cm, and interior column.s } \\
50 / 50 \mathrm{~cm}\end{array}$ \\
\hline 8 & $\begin{array}{l}\text { The dimensions of all interior } \\
\text { columns of the first five storeys } \\
\text { are } 60 / 60 \mathrm{~cm} \text {, while dimensions of } \\
\text { exterior columns and all columns } \\
\text { of the top three storeys are } 50 / 50 \\
\mathrm{~cm} \text {. Beam dimensions are } 30 / 50 \\
\mathrm{~cm} \text { on the top three storeys, and } \\
40 / 60 \mathrm{~cm} \text { on the first five storeys }\end{array}$ \\
\hline 12 & $\begin{array}{l}\text { Dimensions of interior columns } \\
\text { of the first eight storeys are } \\
75 / 75 \mathrm{~cm} \text {, while dimensions of } \\
\text { exterior columns and all columns } \\
\text { of the top four storeys are } 60 / 60 \\
\mathrm{~cm} \text {. Beam dimensions are } 40 / 65 \\
\mathrm{~cm} \text { on the first eight storeys, } \\
\text { and } 30 / 55 \mathrm{~cm} \text { on the top four } \\
\text { storeysa }\end{array}$ \\
\hline
\end{tabular}

Influences in all R/C frames were obtained on the basis of appropriate seismic forces and gravity loads, using the software program ETABS. These influences were first analyzed and dimensioned in accordance with relevant provisions of EC8, and were then subjected to planar non-linear dynamic analysis using the DRAIN-2DX software [6].

Type 02 elements, in which all plastic deformations are concentrated at element ends, are used in the DRAIN-2DX model. The following values are adopted for effective flexural stiffness of cross-section: $l_{e f}=0.45 l_{g}$ for beams, and $l_{e f}=0.70$ $I_{g}$ for columns ( $/ g$ is the moment of inertia of the gross concrete section). In this way, the effects of stiffness reduction due to concrete cracking and bar yielding, are taken into consideration. The viscous damping matrix for frames is modelled as a linear combination of the frame stiffness matrix and mass matrix and, at that, coefficients are selected in such a way to obtain $5 \%$ of the critical damping value in the first and third response modes. Initial bending moments due to gravity load and P-delta effects are taken into account in the analysis. It is assumed that nonstructural components are separated from the structure and hence that they do not affect the stiffness and strength of the frames. Lengths of individual elements have been adopted as axis to axis lengths, i.e. without infinite stiffness of parts within the joint zones. In this way, the degradation of stiffness due to shearing stresses and diagonal cracking within the joint, and penetration of plastic deformation from longitudinal rebars of beams into the joint zones, is taken into account. More realistic and larger displacements of frame structures are obtained if infinite stiff joint zones are neglected [7].

The uniaxial strength of concrete of $f_{c}^{\prime}=25 \mathrm{MPa}$ (C25/30 class according to EC2) was adopted for all elements. The yield strength of longitudinal reinforcing steel was $f_{y}=$ $400 \mathrm{MPa}$, while it amounted to $f_{y}=240 \mathrm{MPa}$ for transverse reinforcement. Plastic hinges were modelled in accordance with bilinear hysteresis rules, with strengthening in the plastic region. The ratio of stiffness in the plastic zone to stiffness before yield, determined during the moment-curves analysis of the cross section using the Xtract software [8], ranged from 0.021 to 0.027 . The constant value of 0,025 was adopted for all beams, because the dynamic analysis results are not very sensitive to the variation of this parameter.

The total weights and fundamental natural periods for all frames are given in the Table 1.

Table 1. Characteristics of frames with different number of storeys

\begin{tabular}{|c|c|c|c|c|}
\hline Frame & 4 & 6 & 8 & 12 \\
\hline Weight [kN] & 2852 & 4561 & 6397 & 10.189 \\
\hline $\begin{array}{c}\text { Fundamental } \\
\text { period } \mathrm{T}_{1}[\mathrm{~s}]\end{array}$ & 1,024 & 1,208 & 1,702 & 2,579 \\
\hline
\end{tabular}

\section{Seismic hazard analysis and selection of earthquake records}

In the probabilistic framework, the earthquake intensity is defined with the same probability of exceedance that is used for the performance objective, meaning that earthquakes 
with the probability of exceedance of $10 \%$ in 50 years would be selected for the Collapse Prevention performance level. Despite the fact that the peak ground acceleration is the basic ground motion intensity measure in EC8, the spectral response acceleration at the fundamental period of the building $S_{a}\left(T_{1}\right)$ has been selected in this paper as the intensity measure (just like in document [3]). This intensity measure has proven to be much better than the peak ground acceleration in case of frame buildings, [13]. However, it should be noted that the described procedure does not depend on the selection of the intensity measure only.

It is interesting to note that in some documents (such as in [3]) the higher performance level - Fully Operational - is attributed to earthquakes with the return period of 475 years. This performance level implies some minor beam damage in form or cracks, and local yield of reinforcement, but the bearing capacity and stiffness after the earthquake must remain at the level similar to that present prior to earthquake. On the other hand, both local and global collapse prevention is required in case of an earthquake with the 2475 year return period (probability of exceedance is $2 \%$ in 50 years). For this reason, frame behaviour is analyzed in this paper with regard to two earthquake intensities: with the return period of 475 years $(10 \% / 50)$ and 2475 years ( $2 \% / 50)$.

A total of 20 ground motions, required for analyses of RC frames, were selected from the European strong-motion database, [11]. These motions were characterized by surfacewave magnitudes, $M_{s}$, ranging from 6.16 to 7.04 , and closest distances to the rupture surface, $R$, ranging from 17 to 30 $\mathrm{km}$. In addition, all selected earthquake ground motions were recorded in stiff soil or rock, with shear-wave velocity $V_{s}$ in excess of $360 \mathrm{~m} / \mathrm{sec}$, which corresponds to soil classes $A$ and $B$ according to the EC8 classification. All ground motion records were examined and checked and care was taken to avoid near field ground-motion effects, as these effect would require a separate analysis, due to their specific nature.

In order to match the EC8 design spectrum, these records were scaled as a set (i.e. all earthquake records were scaled by the same constant) by a factor of six, for a 475-year return period. Without this scaling, the studied frames would have responded in the elastic range during many earthquakes included in this set. The scaling factor 6 was obtained as the greatest value from requirements b) and c) contained in section 3.2.3.1.2(4) of the EC8. In this paper, earthquake records were not individually scaled to make their intensities (measured by peak ground acceleration) compliant with the EC8 linear spectrum. Instead, to cover a wider range of frame behaviour, only the median of all scaled response spectra was matched to the EC8 spectrum. This has enabled verification of frame performance with regard to earthquakes whose intensities are either smaller or greater when compared to the design intensity.

Because the EC8 does not consider such large seismic intensity with the return period of 2475 years, selected recent literature was used for the definition of adequate earthquakes: [9] and [10] - section 2.6.1.3. In this case, all earthquakes were scaled by the factor of 12 , and so the median obtained for earthquakes $2 \% / 50$ is two times as high as the median for earthquakes $10 \% / 50$.

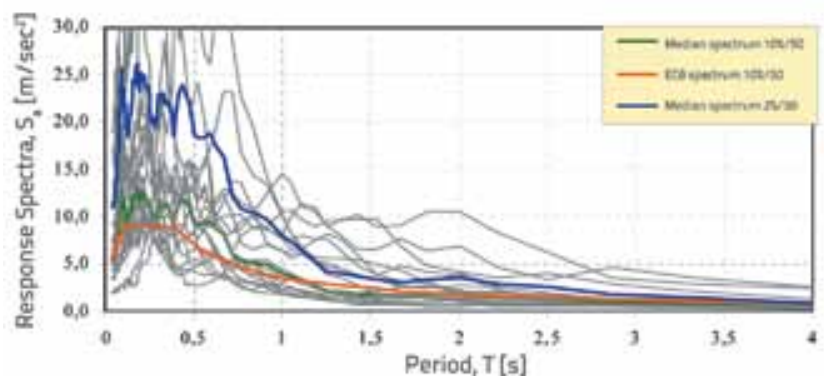

Figure 1. Response spectra of the selected ground motions, and theirs medians for intensities $2 \% / 50$ and $10 \% / 50$

Figure 1 shows spectra medians for 20 scaled ground motions for two levels of intensity, $2 \% / 50$ and $10 \% / 50$, and the designed spectrum EC8 which corresponds to the 10 $\% / 50$ intensity. Scaled ground motion spectra $10 \% / 50$ are marked by thin gray lines. These lines indicate that, although earthquakes were chosen with narrow limits for $M$ and $R_{\text {, }}$ their spectra vary greatly from one another.

The probability of occurrence of various ground motion intensity levels over a given period of time can be defined by means of a seismic hazard curve. The seismic hazard curve $H_{S a}\left(S_{a}\right)$, for spectral acceleration $S_{a}=S_{a^{\prime}}$ is defined as the mean annual frequency (or annual probability for rare events, which is the case in our analysis, [4]) indicating that the intensity of future ground motion events occurring at the site is greater than or equal to the specific value $S_{a^{\prime}}$ (cf. Figure 2). Experts in the field of seismology and/or geology are responsible for defining this curve, while it is the task of civil engineers to predict the seismic response of earthquakes.

It is useful to approximate the hazard curve for the region of interest by the following relation:

$$
H_{s a}\left(s_{a}\right)=P\left[S_{a}>s_{a}\right]=k_{0} s_{a}^{-k}
$$

The value $k$ of the hazard curve slope (which is a straight line in the logarithmic scale) varies from 1 for regions with smaller seismic intensities, to 3 for regions of high seismic intensity. The value 4 of the slope $k$ is suggested for deterministic approach in document [3], and this regardless of the location of seismic intensity.

Coefficients $k_{0}$ and $k_{1}$ needed for defining the seismic hazard curve given in equation (2), can easily be calculated if spectral response acceleration values for the intensities 10\%/50 and $2 \% / 50$ are known. For instance, in case of an 8-storey frame with the fundamental period of $T_{1}=1.702 \mathrm{sec}$, the spectral response acceleration values are $S_{a}=1.555 \mathrm{~m} / \mathrm{sec}^{2}$ for $10 \% / 50$ intensity, and $S_{a}=3.110 \mathrm{~m} / \mathrm{sec}^{2}$ for $2 \% / 50$ intensity (cf. Figure $1)$, and so the coefficients $k_{o}$ and $k$ can be expressed as follows: 
$k=\frac{\ln \left[\frac{H_{S a 10 \%}}{H_{S a 2 \%}}\right]}{\ln \left[\frac{S_{a 2 \%}}{S_{a 10 \%}}\right]}=\frac{1,658}{\ln \left(\frac{3,110}{1,555}\right)}=\frac{1,658}{0,693}=2.39$

$k_{0}=\frac{0,0021}{1,555^{-2.39}}=0,00578$

In expressions (3) and (4), annual probabilities of exceedance for $10 \% / 50$ and $2 \% / 50$ intensities are taken as reciprocal values of appropriate return periods: $H_{S a}\left(S_{a, 10 \%}\right)=1 / 475=0,0021$ and $H_{S a}\left(S_{a, 2 \%}\right)=1 / 2475=0,00040$. Using the calculated coefficients $k$ and $k_{a^{\prime}}$ the seismic hazard curve can easily be defined. This curve is presented in Figure 2 as a straight line with regard to the logarithmic scale. In this paper, the logarithmic slope $k$ will be used for calculating the factor of variability of seismic response, $\gamma$, and the factor of uncertainty of seismic analysis, $\gamma_{\mathrm{a}}$.

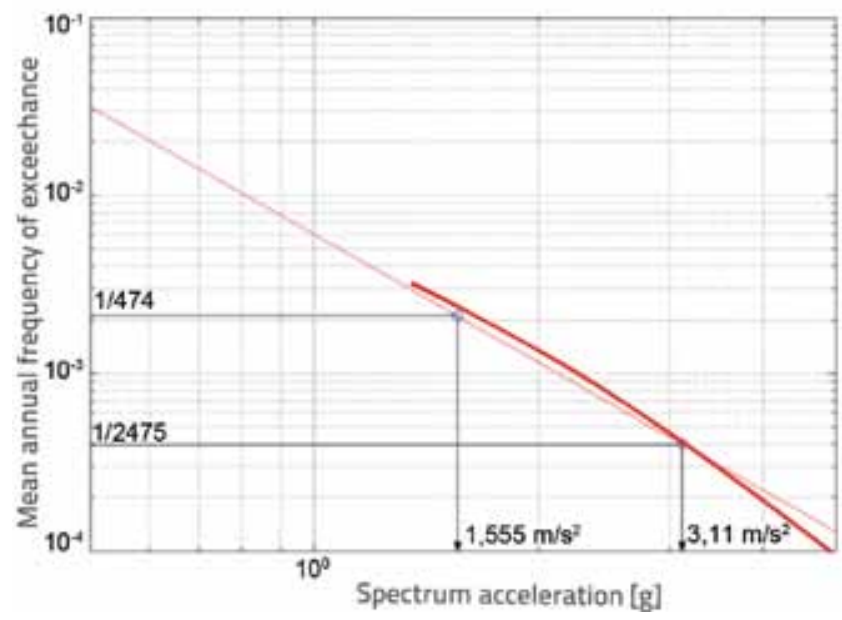

Figure 2. Seismic hazard curve for spectral response acceleration

Values of the median spectral response accelerations are calculated (cf. Figure 1) for all frame structures. These values are used to calculate the logarithmic slopes k, based on the above-described procedure. Appropriate values for $S_{a}$ and $k$ are shown in the Table 2.

\section{Seismic responses of R/C frames}

Seismic response can be calculated by using any of the standard methods of seismic analysis. Linear and nonlinear methods, as well as static and dynamic ones, can be used. During these analyses, in addition to calculating the median of the seismic response $\hat{D}$, it is also necessary to calculate the factor of variability $\gamma$ and the factor of uncertainty $\gamma_{a}$ of seismic responses (cf. expression (1)).

\subsection{Dependence of structural response on seismic intensity}

The seismic response of $R / C$ frames is presented through the maximum interstorey drift for the entire frame (largest storey drift divided by storey height), IDR $R_{\max }$. This seismic response parameter is nowadays very often used in literature as the collapse indicator.

The forms of distribution functions, mean values, and dispersion of results, must be obtained in order to define probabilistic format for the assessment of seismic response. This can be done through statistical processing of nonlinear dynamic analysis results for the chosen set of earthquakes. Previous research [12] and [13] has shown that seismic responses (here $I D R_{\max }$ ) obtained by nonlinear seismic analysis are characterized by lognormal distribution. The basic parameters that define the lognormal distribution are median and dispersion. The statistical parameter median is used for defining the "dominant" or "central" value in lognormal distribution. The advantage of median, when compared to mean value which is very often a "central" value, is its non-sensitivity to the effects of extreme (usually doubtful) seismic response values. The natural measure of dispersion for lognormal distribution is the standard deviation of natural logarithms of results, and this standard deviation is used in this paper.

Nonlinear dynamic analysis results for forty earthquakes representing two seismic intensity cases, $10 \% / 50$ and 2\%/50, are shown in Figures 3 and 4, where each marker corresponds to one pair $\left(I D R_{\max } S_{a}\right)$. The regression analysis of results shows that the dependence between seismic response and seismic intensity can best be described using the following function:

Table 2. Spectral response accelerations for two intensities and logarithmic slopes $\boldsymbol{k}$

\begin{tabular}{|c|c|c|c|}
\hline Number of storey R/C frame & $\begin{array}{c}S_{a}(10 \% / 50) \\
{\left[\mathrm{m} / \mathrm{s}^{2}\right]}\end{array}$ & $\begin{array}{c}S_{a}(\mathbf{2} \% / 50) \\
{\left[\mathrm{m} / \mathrm{s}^{2}\right]}\end{array}$ & 2.428 \\
\hline 12 & 1,229 & 3.110 & 2,44 \\
\hline 8 & 1,555 & 4.524 & 2,46 \\
\hline 6 & 2.308 & 6.344 & 2,69 \\
\hline
\end{tabular}




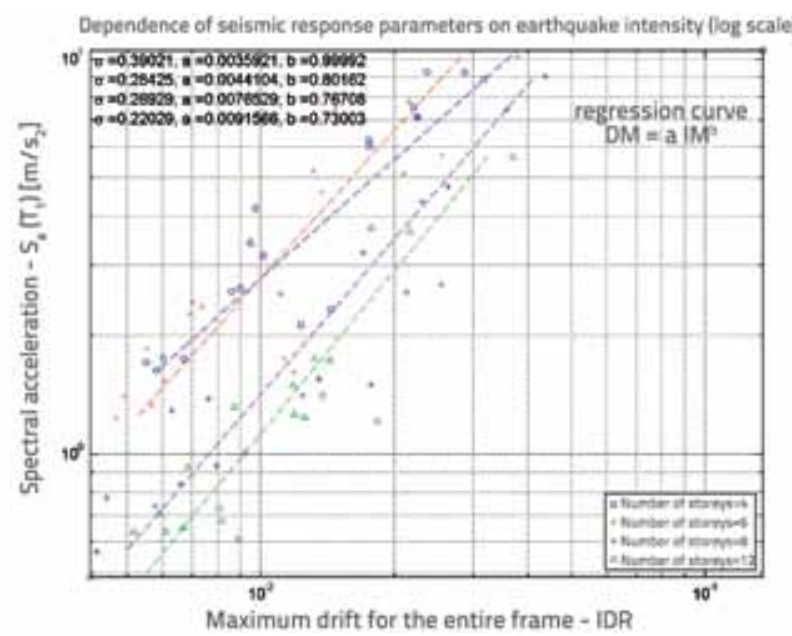

Figure 3. Nonlinear dynamic analysis results of R/C frames subjected to 20 earthquakes of the intensity $10 \% / 50$ and adequate regression fits

$I D R_{\max }=a\left(S_{a}\right)^{b}$

which represents the straight line in the log-log scale. Values for dispersions $S_{D R}$ (DR in subscript refers to demand and randomness) and coefficients $a$ and $b$, are shown in Figures. 3 and 4 for all analyzed frames. The dispersion is defined as the standard deviation of natural logarithms of the residuals $I D R_{\text {max, }}$ from the regression line (equation (5)) and it is calculated using:

$\sigma_{D R}=\sqrt{\frac{1}{n-1} \sum_{i=1}^{n}\left(\ln I D R_{\max , i}-\ln I \hat{D} R_{\max , i}\right)^{2}}$

where:

$I D R_{\text {max }, i}$ - seismic responses obtained

$I \hat{D} R_{\max , i}$ - points on regression line that can be calculated from the equation:

$\ln \left(I \widehat{D} R_{\max , i}\right)-\ln (a)+\mathrm{b} \ln \left(S_{a, i}\right)$.

If seismic response results for lower intensity earthquakes (10\%/50, cf. Figure 3) are compared with higher intensity earthquakes ( $2 \% / 50$, cf. Figure 4 ), it can be seen that the dispersion of results increases with an increase in earthquake intensity i.e. with an increase of nonlinear deformations.

Moreover, the results also indicate that a higher earthquake intensity has a higher coefficient $b$. This could be due to two reasons. The first one is that $\mathrm{P}$-delta effects at intensities $2 \% / 50$ were more significant, and displacements increased faster than the intensity (in that way the value $b$ was also increased). The second reason is that "hardening" effects were registered for the lower intensities of earthquakes $(10 \% / 50)$. The system hardening occurs when $I D R_{\max }$ of a frame becomes smaller even though the ground motion

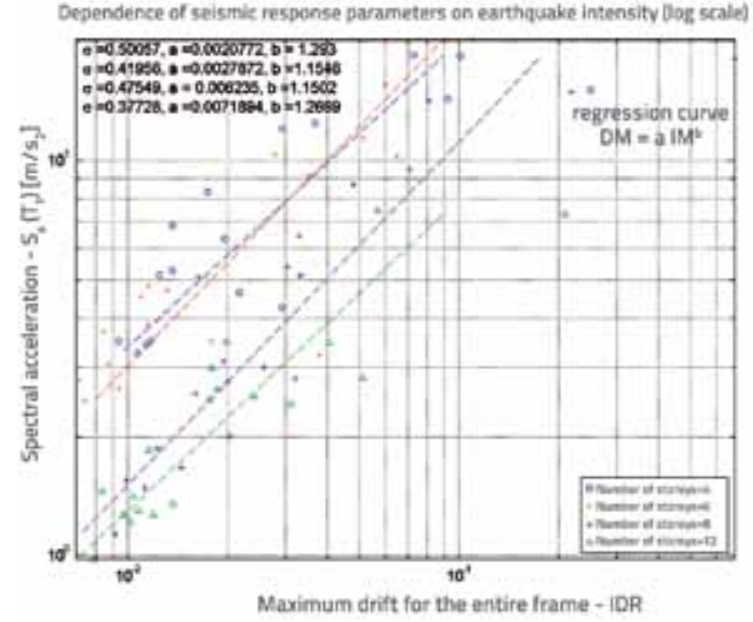

Figure 4. Nonlinear dynamic analysis results of R/C frames subjected to 20 earthquakes of the intensity $2 \% / 50$ and adequate regression fits

intensity gradually increases, thus reducing the value of coefficients $b$. The hardening effect can be explained as follows. In case of smaller intensities, the frame experiences the very first (and in this case the only) nonlinear deformations (and hence maximum drifts) at the upper storeys. In case of stronger intensities, non-linear deformations "move" to the lower third of the structure. The hardening occurs when, upon increasing the intensity of earthquake, maximum storey drifts at lower storeys are not sufficiently strong to exceed the previously recorded maximum values at upper storeys. Analyses conducted in [13] show that the hardening decreases with an increase in the number of storeys, and so it does not occur at all in case of a 12-storey frame.

\subsection{Uncertainty and randomness in estimating seismic response}

It has been observed that the structure exhibits significant differences in behaviour when subjected to apparently similar earthquake records, even if the records are normalized on the same intensity. As future earthquakes at a location of interest can not accurately be predicted, it is necessary to account for this difference in seismic response in case of different earthquakes of the same intensity on a given location. This variability in seismic response is taken into account by means of the coefficient $\gamma$ (cf. expression (1)) which is defined, according to [4], as follows:

$$
\gamma=e^{\frac{k}{2 b} \sigma_{D R}^{2}}
$$

where:

$k \quad$ - logarithmic slope of the hazard curve; cf. expressions (2) and (3) 
b - coefficient that defines the increase of seismic response as related to seismic hazard (cf. expression (5)

$\sigma_{D R}$ - standard deviation of natural logarithms of seismic responses; cf. equation (6).

Diagrams given in Figures 3 and 4 show the dispersion, $\sigma_{\mathrm{DR}^{\prime}}$ and the coefficient $b$. These values are once again presented, for clarity reasons, in Table 3 together with calculated values for the variability factor $\gamma$.

Although the higher value of coefficient $b$ reduces the factor of variability $\gamma$, this factor is higher for earthquakes of greater intensity, primarily because of greater dispersion $\sigma_{D R}$. This observation is applicable for all four frames analyzed in this paper.

Unlike the factor $\gamma$ which accounts for randomness, the factor $\gamma_{a}$ is introduced to account for uncertainty which is present in the evaluation of seismic response of structures. The uncertainty is due not only to our inability to obtain a mathematical model that matches exactly all physical characteristics of the structure, but also to the limited number of tests/analyses used in the calculation of $\sigma_{D R}$. The errors are made during estimation of bearing capacity, stiffness, viscous damping, effects of non-structural components, weight of structure at the moment of earthquake action, etc. By varying the values of the above parameters and by defining the set of different models of the structure, the influence of the variations of a particular parameter on the uncertainty in the response can be calculated. The measure of the result dispersion is the standard deviation of natural logarithms of seismic responses, denoted by $\sigma_{D U}(D U$ in subscript refers to demand and uncertainty).

The error in the sense of deviation from the mean value of seismic responses, registered by means of less accurate analytic methods, is accounted for with the help of the factor $C_{B}$ which is given as follows:

$C_{B}=$ response predicted by nonlinear time history analysis
Now the factor of uncertainty $\gamma_{a}$ is defined as [4]:

$\gamma_{a}=C_{B} e^{\frac{k}{2 b} \sigma_{D U}^{2}}$

It is considered that the total measure of uncertainty $\sigma_{\mathrm{DU}}$ is composed of the following parts:

$\sigma_{\mathrm{NDA}}$ - uncertainty about the level at which the nonlinear dynamic analysis represents the real behaviour

$\sigma_{\text {PRIG }}$ - uncertainty in the estimation of viscous damping

$\sigma_{\text {MASA }}$ - uncertainty in the estimation of weight (mass)

$\sigma_{\text {MATE }}$ - uncertainty in the estimation of material characteristics (concrete and steel)

$\sigma_{\mathrm{OBA}}$ - uncertainty due to limited number of test or simulation runs which is equal to $\sigma_{O B A}=\frac{\sigma_{D R}}{\sqrt{n}}$, where $\mathrm{n}$ is the number of tests, and $\sigma_{\mathrm{DR}}$ dispersion, whose values are given in Table 3 for the analyzed frames.

Uncertainty values $\sigma_{\mathrm{PRIG}} \sigma_{\mathrm{MASA}}$ and $\sigma_{\mathrm{MATE}^{\prime}}$ can be estimated according to the influence of individual variable parameters on the uncertainty of seismic response, $[14,15]$. In fact, by varying particular parameter (damping, mass and material characteristics) during these analyses, the $16 \%, 50 \%$ and $84 \%$ fractions of seismic response are obtained and the dispersion can be easily calculated, under assumption of lognormal distribution. All mentioned uncertainties for all frames considered are calculated in [13] and shown in Table 4.

Even though highly accurate nonlinear dynamic analyses were used during estimation of seismic response of $\mathrm{R} / \mathrm{C}$ frames, the analysis performed is still not ideal, primarily because it neglects the effect of deterioration, i.e. degradation of stiffness and bearing capacity during cyclic and repeated loading of structures. The following values are adopted for this uncertainty $\sigma_{\mathrm{NDA}}: 0.12,0.14,0.16$, and 0.20 for 4, 6, 8 and 12-storey R/C frames, respectively (cf. Table 4). The values suggested are based on some earlier tests [16]. Increased uncertainty values were adopted for high-rise frames because the combination of P-delta effects and deterioration would be greater for these structures. At the same time, to be on the side of safety, the suggestion

Table 3. Dispersion values $\mathrm{s}_{\mathrm{DR}^{\prime}}$ coefficients $\mathrm{b}$, and factors of variability $g$, for two levels of intensity

\begin{tabular}{|c|c|c|c|c|c|c|}
\hline \multirow{2}{*}{$\begin{array}{c}\text { Number of storey R/C } \\
\text { frame }\end{array}$} & \multicolumn{2}{|c|}{$\sigma_{\mathrm{DR}}$} & \multicolumn{2}{|c|}{$b$} & \multicolumn{2}{|c|}{$\gamma$} \\
\hline & $10 \% / 50$ & $2 \% / 50$ & $10 \% / 50$ & $2 \% / 50$ & $10 \% / 50$ & $2 \% / 50$ \\
\hline 12 & 0,220 & 0,377 & 0,730 & 1,267 & 1,08 & 1,15 \\
\hline 8 & 0,269 & 0,475 & 0,767 & 1,150 & 1,12 & 1,26 \\
\hline 6 & 0,284 & 0,420 & 0,802 & 1,155 & 1,13 & 1,21 \\
\hline 4 & 0,390 & 0,501 & 1,000 & 1,293 & 1,23 & 1,30 \\
\hline
\end{tabular}


that inclusion of deterioration effect in the calculation would increase the $I D R_{\max }$ for $10 \%$, was adopted, i.e. the factor $C_{B}$ was set to 1.1, cf. expression (8).

The total measure of uncertainty, $\sigma_{\mathrm{Du}}$ is obtained as the root of the sum of squares of individual dispersions, (see Table 4), under assumption of non-correlation between individual dispersion parameters. If future research shows that the assumption of non-correlation is unjustified, the use of probabilistic methodology will not be compromised, and this correlation can subsequently be included in the calculation without significant difficulty.

Knowing the total uncertainty $\sigma_{\mathrm{DU}}$ (Table 4), the coefficient $b$ (Table 3), logarithmic slope $k$ (Table 2), and factor $C_{B}=1.1$, the factor of uncertainty $\gamma_{a}$ can be calculated using equation (9).

The final results of this analysis, as given in Table 5 , are the factors of variability, $\gamma$, the factors of uncertainties, $\gamma_{a}$, as well as the $I D R_{\max }$ values, which are obtained using the regression formula $I D R_{\max }=\mathrm{a} S_{a}{ }^{\mathrm{b}}$, where the values of the coefficients $a$ and $b$ are taken from Figs. 3 and 4 , and values $S_{a}$ from Table 2 . The corrected seismic response $\gamma \gamma_{a} I D R_{\max }$ is given in the last column of Table 5.

If we compare evaluation of the first order seismic response $I D R_{\text {max }}$ in which uncertainty and randomness are not taken into account, with the response $\gamma \gamma_{a} I D R_{\text {max }}$ that takes into account the uncertainty and randomness, it can be seen from Table 5 that the seismic response increases from 31 to $54 \%$. In order to control exceedance of performance objective - Collapse Prevention, it is necessary to compare the seismic response obtained in this way with the reduced structure deformation capacity, all in accordance with the expression (1). In fact, the interstorey drift ratios would fulfil requirements given in [1], $(E C 8,4.4 .3 .2 .(1 \mathrm{c}))$, i.e. $I D R_{\max } \leq 2 \%$ for buildings having nonstructural elements fixed in a way so as not to interfere with structural deformations, but not requirements for buildings having non-structural elements of brittle materials attached to the structure, where $I D R_{\max } \leq 1 \%$. The above conclusion is of course related to the design intensity of $10 \% / 50$ according to EC8, with the reduction factor $v$ amounting to 0.5 .

\section{Conclusions}

Nowadays, it is quite common to conduct the seismic hazard analysis in probabilistic format, in order to taken into account the influence of uncertainties and randomness during evaluation of seismic load. This approach is also used in EC8. However, verification of seismic behaviour is conducted in deterministic manner in current seismic codes. Knowing that uncertainties and randomness are also present in the evaluation of seismic behaviour, it can reasonably be

Table 4. Individual and total uncertainties at the considered frames

\begin{tabular}{|c|c|c|c|c|c|c|c|c|}
\hline \multirow{2}{*}{$\begin{array}{c}\text { Number of storey R/C } \\
\text { frame }\end{array}$} & \multirow{2}{*}{$\sigma_{\mathrm{NDA}}$} & \multirow{2}{*}{$\sigma_{\mathrm{PRIG}}$} & \multirow{2}{*}{$\sigma_{\text {MASA }}$} & \multirow{2}{*}{$\sigma_{\text {MATE }}$} & \multicolumn{2}{|c|}{$\sigma_{\mathrm{OBA}}$} & \multicolumn{2}{|c|}{$\sigma_{\mathrm{DU}}$} \\
\hline & & & & & $10 \% / 50$ & $2 \% / 50$ & $10 \% / 50$ & $2 \% / 50$ \\
\hline 12 & 0,20 & 0,08 & 0,10 & 0,01 & 0,05 & 0,08 & 0,24 & 0,25 \\
\hline 8 & 0,16 & 0,17 & 0,16 & 0,05 & 0,06 & 0,11 & 0,29 & 0,31 \\
\hline 6 & 0,14 & 0,13 & 0,04 & 0,03 & 0,06 & 0,09 & 0,21 & 0,22 \\
\hline 4 & 0,12 & 0,15 & 0,05 & 0,06 & 0,09 & 0,11 & 0,23 & 0,23 \\
\hline
\end{tabular}

Table 5. Values of the factor of variability $\gamma_{a^{\prime}}$ factor of uncertainty $\gamma_{a} I D R_{\max }$ and $\gamma \gamma_{a} I D R_{\max }$ for the considered frames

\begin{tabular}{|c|c|c|c|c|c|c|c|c|}
\hline \multirow{2}{*}{$\begin{array}{c}\text { Number of storey R/C } \\
\text { frame }\end{array}$} & \multicolumn{2}{|c|}{$\gamma$} & \multicolumn{2}{|c|}{$\gamma_{a}$} & \multicolumn{2}{|c|}{ IDR $_{\text {max }}$} & \multicolumn{2}{c|}{$\gamma \gamma_{a}$ IDR $_{\text {max }}$} \\
\cline { 2 - 9 } & $10 \% / 50$ & $2 \% / 50$ & $10 \% / 50$ & $2 \% / 50$ & $10 \% / 50$ & $2 \% / 50$ & $10 \% / 50$ & $2 \% / 50$ \\
\hline $\mathbf{1 2}$ & 1,08 & 1,15 & 1,21 & 1,17 & $1,06 \%$ & $2,21 \%$ & $1,39 \%$ & $2,97 \%$ \\
\hline $\mathbf{8}$ & 1,12 & 1,26 & 1,25 & 1,22 & $1,06 \%$ & $2,25 \%$ & $1,48 \%$ & $3,46 \%$ \\
\hline $\mathbf{6}$ & 1,13 & 1,21 & 1,18 & 1,16 & $0,86 \%$ & $1,59 \%$ & $1,15 \%$ & $2,23 \%$ \\
\hline $\mathbf{4}$ & 1,23 & 1,30 & 1,18 & 1,16 & $1,23 \%$ & $2,26 \%$ & $1,79 \%$ & $3,41 \%$ \\
\hline
\end{tabular}


assumed that the probabilistic approach will soon expand to these phases of structural analysis and design.

In this paper, the probabilistic format proposed in document FEMA 351 is applied in the evaluation of seismic performance of $\mathrm{R} / \mathrm{C}$ frame structures, with different number of storeys, designed in line with EC8. The results obtained point to advantages of using the probabilistic format, because interstorey drift ratios (seismic response parameter used in this paper) have increased by as much as $54 \%$. Further investigations carried out in this field by the authors, concern probabilistic verification of limit state of collapse, i.e. comparison of probable seismic response (shown in this paper) with probable deformation capacity of $R / C$ frame structures. This will enable further estimation of the level of safety to seismic load, as ensured by EC8 for this type of structures.

\section{REFERENCES}

[1] EN 1998-1: 2004: Eurocode 8: Design of Structures for Earhquake Resistance, Part 1: General Rules, Seismic Actions and Rules for Buildings, CEN, Brussels, 2004

[2] Fardis, M.; Carvalho, E.; Elnashai, A.; Faccioli, E.; Pinto, P.; Plumier A.: Designers' Guide to EN 1998-1 and EN 1998-5, Eurocode 8: Design of Structures for Earthquake resistance, General rules, seismic actions, Design Rules for Buildings, Foundations and Retaining Structures, 2005.

[3] FEMA 351: Recommended Seismic Evaluation and Upgrade Criteria for Existing Welded Steel Moment-Frame Buildings, Federal Emergency Management Agency, Washington, D.C., 2000.

[4] Jalayer, F.: Direct Probabilistic Seimic Analysis: Implementing Non-linear Dynamic Assessments, Doctoral Dissertation, Stanford University, Stanford, 238 pp., 2003.

[5] EN 1992-1-1:2004; Eurocode 2: Design of Concrete Structures-Part 1-1, General Rules and Rules for Buildings, CEN, Brussels, 2004.

[6] Powell, G.: DRAIN-2DX: Element Description and User Guide for Element Type01, Type02, Type04, Type06, Type09 and Type15, Version 1.10., Report number UCB/SEMM-93/18. Department of Civil Engineering. University of California. Berkeley., 1993.

[7] Paulay, T.; Priestley, M. J. N.: Seismic Design of Reinforced Concrete and Masonry Buildings, John Wiley \& Sons, 744 pp., 1992.

[8] Chadwell, C.: UCFyber Version 2.4.1, Zevent, Berkeley, California, 2000.

[9] Cornell, C.A.; Luco, N.: The Effect of Connection Fractures on Steel Moment Resisting Frame Seismic Demands and Safety, Report on SAC Phase II Task 5.4.6 - Final Draft, Stanford University, Stanford, 207 pp., 1999.
[10] FEMA 273: NEHRP Guidelines for the Seismic Rehabilitation of Buildings, Federal Emergency Management Agency, Washington, D.C., 1997.

[11] Ambraseys, N.; Smit, P.; Berardi, R.; Rinaldis, D.; Cotton, F.; BergeThierry, C.: Dissemination of European Strong-Motion Data, CDROM collection, European Council, Environment and Climate Research Programme, 2000.

[12] Shome, N.: Probabilistic Seimic Demand Analysis of Nonlinear structures, Doctoral Dissertation, Stanford University, Stanford, 320 pp.,1999.

[13] Janković, S.: Probabilistička Seizmička analiza armirano betonskih ramovskih konstrukcija, doktorska disertacija, Građevinski fakultet u Podgorici, Univerzitet Crne Gore, 202. str., 2004.

[14] Porter, K.A.; Beck, J.L.; Shaikhutdinov, R.V.: Invastigation of Sensititivity of Building Loss Estimates to Major Uncertain Variables for the Van Nuys Testbed, Pacific Earthquake Engineering Research Center, University of California, Berkeley, University of California, Berkeley, 41 pp., 2002.

[15] Lee, T.H.; Mosalam, K.M.: Sensitivity of Seismic Demand of a Reinforced Concrete Shear-Wall Building, Ninth International Conference on Applications of Statistics and Probability in Civil Engineering (ICASP9), San Francisko, 2003.

[16] Yun, S.Y.; Hamburger, R.O.; Cornell, C.A.; Foutch, D.A.: Seismic Performance Evaluation for Steel Moment Frames, ASCE Journal of Structural Engineering, Volume 128, Issue 4, 12p, 2002. 